\title{
Correlates of protection efficacy induced by vaccinia virus- specific CD8+ $T$ cell epitopes in the murine intranasal challenge model
}

\author{
Magdalini Moutaftsi ${ }^{1}$, Shahram Salek-Ardakani ${ }^{2}$, Michael Croft $^{2}$, Bjoern Peters ${ }^{1}$, John \\ Sidney ${ }^{1}$, Howard Grey ${ }^{1}$, and Alex Sette ${ }^{1}$ \\ ${ }^{1}$ Division of Vaccine Discovery, La Jolla Institute for Allergy and Immunology, LaJolla, California, \\ USA \\ 2 Division of Molecular Immunology, La Jolla Institute for Allergy and Immunology, LaJolla, \\ California, USA
}

\section{Abstract}

The recent identification of a large array of different vaccinia virus (VACV)-derived CD8 ${ }^{+} \mathrm{T}$ cell epitopes offers a unique opportunity to systematically analyze the correlation between protective efficacy and variables such as kinetics of expression and function of viral proteins, binding affinity to $\mathrm{MHC}$ molecules, immunogenicity and viral antigen processing/presentation. In the current study, 49 different $\mathrm{H}-2^{\mathrm{b}}$ restricted epitopes were tested for their ability to protect peptideimmunized C57B1/6 mice from lethal i.n. challenge with VACV. The epitopes varied greatly in their ability to confer protection, ranging from complete protection with minimal disease to no protection at all. The function or kinetics of the viral antigen expression did not correlate with protective efficacy. However, binding affinity partially predicted protection efficacy and ultimately epitope immunogenicity and recognition of infected cells offered the best correlation.

\section{Keywords}

CD8 ${ }^{+} \mathrm{T}$ cell epitopes; immunogenicity; intranasal challenge model; Protection efficacy VACV

\section{Introduction}

\begin{abstract}
Immunization with vaccinia virus (VACV) confers protection against smallpox due to a multi-specific humoral and cellular immune response. Even though T cell immunity is key in mediating viral clearance upon primary infection, and also directly contributes towards establishing a protective immune response [1-4], the exact contribution of different $\mathrm{T}$ cell specificities has not been elucidated. Few studies addressed the role of epitope-specific $\mathrm{CD}^{+} \mathrm{T}$ cells in conferring protection from lethal poxvirus infection by using a mouse model of protection. Drexler et al [5], showed that HLA-A*0201 (HHD) transgenic mice were not protected from challenge following peptide-immunization with a VACV-specific HLA-A*0201-restricted T cell epitope. In contrast, studies by Snyder et al and Tscharke el al $[6,7]$ demonstrate that peptide-immunization with a VACV-specific $\mathrm{CD} 8^{+} \mathrm{T}$ cell epitope protected mice with varying degrees from VACV challenge, suggesting that protection may vary as a function of the epitope selected for study.
\end{abstract}

Full correspondence: Alessandro Sette, La Jolla Institute for Allergy and Immunology, La Jolla, CA 92037, USA, Fax: +1-858-752-6985, alex@liai.org.

Conflict of interest: The authors declare no financial or commercial conflict of interest. 
Numerous factors are key in generating immunologically relevant CTL epitopes, including efficiency of peptide binding affinity to MHC molecules and the efficiency by which the epitope is generated by antigen processing, availability of an appropriate TCR repertoire, and variations in $\mathrm{CD} 8^{+} \mathrm{T}$ cell precursor frequencies [8]. Additional factors might dictate whether a given epitope is associated with high or low protective capacity. Antigen expression and presentation kinetics may play an important role in determining the protective capacity of an epitope because early epitope display on the surface of infected cells, might allow early recognition and elimination of infected cells by $\mathrm{CD} 8^{+} \mathrm{T}$ cells. Indeed, it has been shown that $\mathrm{CD} 8^{+} \mathrm{T}$ cell responses preferentially target early expressed VACV genes [9-11] and that the immunogenicity of recombinant proteins under early vs. late VACV promoters influenced the expression of the respective genes [12], suggesting that early expressed antigens may be better targets for induction of protective responses.

Differential antigen expression in different APCs might also influence protective capacity. It has been shown that VACV preferentially targets both human and murine DC for infection [13-15]. However, in contrast to non-professional APC, such as keratinocytes, that support complete viral life cycle [14], VACV infection of DC is abortive and is characterized by early but not late viral gene expression [16-18]. This is particular relevant in the context of protection, as it has been shown in the influenza system that antigen presentation of the same protein differs in DC vs. non-professional APC. This resulted in the generation of antigen-specific $\mathrm{T}$ cells that were unable to recognize antigens at the site of infection during recall responses. More importantly, vaccination with an epitope expressed exclusively by DC and not at site of infection had a detrimental effect on antiviral immunity [19,20]. Therefore, viral gene expression kinetics and antigen presentation variation between different cell types may be interconnected and depend on permissiveness for viral replication of the infected cell type.

Despite the fact that $\mathrm{CD} 8^{+} \mathrm{T}$ cell responses have been shown to be involved in controlling poxvirus infections both in humans and animal models, there is limited knowledge about the correlates of protective efficacy. The recent identification of a large array of VACV-specific $\mathrm{CD} 8^{+} \mathrm{T}$ cell epitopes in C57BL/6 mice [9] offered a unique opportunity to systematically and comprehensively analyze the correlation of protective efficacy induced by individual epitopes.

\section{Results and Discussion}

\section{Wide variation in protection efficacy induced by individual epitopes}

To screen all $49 \mathrm{H}-2^{\mathrm{b}}$-restricted, previously defined [9] (Supporting Information Table 1) $\mathrm{CD} 8^{+} \mathrm{T}$ cell epitopes for protective efficacy, we modified the i.n. challenge mouse model of protection as described by other groups [5-7]. Mice were immunized s.c. once with individual $\mathrm{CD} 8^{+} \mathrm{T}$ cell epitopes in incomplete Freund's adjuvant (IFA), in the presence of an unrelated $\mathrm{CD} 4^{+} \mathrm{T}$ cell helper epitope, similarly as described in a previous study [21], and were challenged with a lethal i.n. dose of VACV 12 days later. Peptide-immunized mice were challenged with lethal i.n. dose of VACV and monitored daily for weight loss.

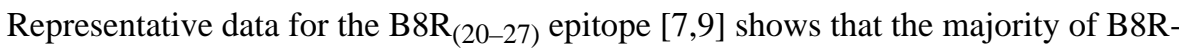
immunized animals survived the infection (89\%) and lost less weight (maximum weight loss $=13 \%$ ) compared to PBS-immunized control group where most animals had rapid weight loss and succumbed to disease (6\% survival) by day 7 (Fig. 1A and B). Thus, peptideimmunization and therefore $\mathrm{CD} 8^{+} \mathrm{T}$ cells conferred a survival advantage compared to nonimmunized mice. 
Upon testing all 49 epitopes in a similar fashion, we observed a range of protection efficacies (Supporting Information Table 1). A total of 15 epitopes protected most of the mice (100-75\%) (Fig. 1C), and 22 more epitopes were significantly but partially protective (75-25\%, $\mathrm{p}<0.05$, see Methods). In contrast, 12 epitopes induced no significant protection $(<25 \%)$. These results are in agreement with recent studies where peptide-immunization with VACV-specific $\mathrm{CD} 8^{+} \mathrm{T}$ cell epitopes was associated with different degrees of protection from lethal poxvirus challenge, suggesting that protection efficacy largely depends on the selection of the epitope [5-7].

\section{Neither kinetics nor function of antigen correlate with protection efficacy}

Next, we explored possible factors that may explain the large variation observed in protective efficacy. We reasoned that differences in kinetics of antigen expression and/or the function of the epitope-containing protein might play a role. VACV gene expression can be broadly divided into immediate-early, early and late genes [22,23]. Accordingly, of the 49 epitope-containing proteins, 10 were immediate-early, 16 were early and 19 were late expressed proteins ( 4 early/late proteins were excluded from the analysis due to low representation). No significant correlation between survival and kinetics of antigen transcription was demonstrable (Fig. 2A; Supporting Information Table 1). One caveat in interpreting the data is that analyzing correlation of protection with kinetics of gene expression refers to RNA synthesis and may not correlate with protein synthesis which may follow distinct kinetics.

We also examined the correlation between protection efficacy with functional category of the viral proteins. In general, VACV proteins can be categorized into virulence factors (potentially modulate host immune responses), regulatory proteins (support viral replication) and structural proteins (usually contained within the virion) [9-11]. Similarly to the observation with the expression kinetics no significant correlation was found between protection efficacy and functional category of the viral antigens (Fig. 2B; Supporting Information Table 1), suggesting that the intrinsic property of the epitopes may dictate protective capacity.

Recently, Kastenmuller et al [24] demonstrated that the expansion of virus-specific CD8 ${ }^{+} \mathrm{T}$ cells was regulated by $\mathrm{T}$ cell cross-competition favoring $\mathrm{T}$ cells during secondary response that were able to rapidly detect infected cells and was heavily influenced by the timing of antigen expression in infected APC, favoring early expressed proteins. In contrast, our data suggest that there is no correlation between protective efficacy of the 49 epitopes and kinetics of expression. This apparent discrepancy is easily resolved considering that only epitopes recognized in the course of natural infection were tested, and that as mentioned above early proteins are preferentially recognized by $\mathrm{CD} 8^{+} \mathrm{T}$ cells. Thus, our data suggest that the apparent superior protective capacity of early proteins is based on their higher immunogenicity, and not in any intrinsic higher protective capacity.

\section{MHC binding and peptide immunogenicity partially predict protection efficacy}

Another factor contributing to the immunogenicity of CTL epitopes is binding affinity for MHC molecules [25]. Correlation of binding affinity based on IC50 values [9] (Supporting Information Table 1) revealed that 13 of the 15 epitopes associated with good protective activity were high-affinity binders (IC50<10 nM) (Fig. 3A). Within the 12 non-protective epitopes 4 were low-affinity binders (IC50>1000 nM), 4 were intermediate (IC50 between 10 and 1000) and 4 were high-affinity binders (Fig. 3A). This correlation is highly significant $\left(r_{\mathrm{s}}=0.56\right)$, and suggests, that high-affinity binding of an epitope to the appropriate MHC molecule is necessary but not sufficient to associate an epitope with high protective efficacy. It further suggests that, besides binding affinity, other specific features 
associated with the epitopes, such as size of TCR repertoire and cellular processing may also contribute to determine protective efficacy.

The use of peptide immunization for inducing VACV responses might bias the result in favor of high affinity binders as the low affinity binders might simply induce lower responses. For this reason, it is important to determine the frequencies of $\mathrm{T}$ cells specific for the various epitopes prior to challenge by the use of tetrameric reagents. This was not performed in the present study due to the considerable effort involved, however, the effector frequencies can be estimated by the magnitude of in vitro IFN- $\gamma$ production by splenocytes before challenge. Therefore, we next examined the correlation between protective efficacy and the magnitude of IFN- $\gamma$ production following peptide-immunization, by stimulating splenocytes from peptide-immunized mice with peptide-pulsed APC. This analysis showed significant, but only marginally better correlation to survival ( $\mathrm{rs}=0.59$ Fig. $3 \mathrm{~B}$ ) compared to the correlation with MHC binding affinity.

\section{Immunogenicity and recognition of infected APC correlate with protective efficacy}

Another factor that might influence whether peptide-immunization would protect against lethal infection is the efficiency with which the epitope is processed and presented on the surface of an infected cell. Accordingly, we measured the immunogenicity of each epitope by testing splenocytes from peptide-immunized mice for their ability to produce IFN- $\gamma$ upon stimulation with fully permissive VACV-infected APC that express both early and late antigens (Assarsson personal communication). This analysis showed the best correlation with protective efficacy $\left(r_{\mathrm{s}}=0.72\right.$; Fig. $\left.3 \mathrm{C}\right)$, suggesting that the intrinsic immunogenicity of the epitope and the efficiency of epitope processing and presentation cooperate to determine the capacity of an epitope to elicit a protective immune response.

\section{Concluding Remarks}

In summary, our data provide important insights regarding the factors that contribute to protective efficacy induced by peptide-immunization by analyzing a comprehensive set of VACV-specific $\mathrm{CD} 8^{+} \mathrm{T}$ cell epitopes that were identified during natural infection (i.p.). Epitopes can be predicted to confer good protection based on immunogenicity of the epitope, which significantly depend on the MHC binding capacity of the epitope, and the efficiency with which the epitope is expressed on the infected cells. These findings are relevant for vaccine evaluation and design studies, particularly, where isolated viral proteins are used as immunogens.

\section{Material and methods}

\section{Peptides and MHC binding assays}

Peptides utilized were synthesized as purified material by Pepscan Systems B.V. (Lelystad, Netherland) and Mimotopes (Minneapolis, MN/Clayton, Victoria, Australia). MHC purification, and quantitative assays to measure binding affinity of peptides to purified $\mathrm{H}-2$ $\mathrm{K}^{\mathrm{b}}$ and $\mathrm{H}-2 \mathrm{D}^{\mathrm{b}}$ molecules were performed as previously described [9].

Viruses-The Western Reserve (WR) strain of VACV was obtained from Bernard Moss (National Institute of Allergy and Infectious Diseases) and grown in $143 \mathrm{TK}^{-}$cells.

\section{Mice}

Specific pathogen-free C57BL/6 mice were obtained from Jackson Laboratories and used between 6-12 weeks of age, following National Institutes of Health guidelines and Institutional Animal Care and Use Committee approved animal protocols. 


\section{Infection and immunizations}

For peptide-immunizations, $\mathrm{C} 57 \mathrm{B1} / 6$ mice were immunized s.c. once at the base of the tail with $10 \mu \mathrm{g}$ of $\mathrm{CD}^{+} \mathrm{T}$ cell peptide epitopes (or PBS control) emulsified in IFA with $140 \mu \mathrm{g}$ HBV core 128-140 (TPPAYRPPNAPIL) epitope in a total volume of $100 \mu 1$. For i.n. challenge, 12 days after peptide-priming mice were inoculated by the i.n. route with a lethal dose of $3 \times 10^{6}$ PFU of VACV-WR in $10 \mu \mathrm{l}$ PBS, weighed daily and euthanized when they lost $25 \%$ of their initial body weight. DC2.4 cells (kindly provided by Kenneth L. Rock) were used as APC for intracellular cytokine staining (ICCS) assays to identify recognition of virally infected $\mathrm{APC}$ by VACV-specific $\mathrm{CD} 8^{+} \mathrm{T}$ cells and were grown and infected as previously described [9]. Briefly, DC2.4 cells $\left(5 \times 10^{6}\right)$ were infected with VACV-WR (MOI of 5) in $200 \mu \mathrm{l}$ of PBS at $37^{\circ} \mathrm{C}$ for $30 \mathrm{~min}$ in a $15 \mathrm{ml}$ Falcon tube with occasional shaking, followed by addition of $9 \mathrm{ml} \mathrm{R} 10$ medium and incubation for another $4 \mathrm{~h}$.

\section{ICCS Assay}

Splenocytes $\left(1 \times 10^{6}\right.$; devoid of red blood cells) from peptide-immunized mice (day 12 postinjection) were incubated with either peptide $(1 \mu \mathrm{g} / \mathrm{ml})$ or $2 \times 10^{5} \mathrm{VACV}$-infected DC2.4 in the presence of brefeldin A $(10 \mu \mathrm{g} / \mathrm{ml})$. After 6 to $12 \mathrm{~h}$ the cells were stained according to the protocol of the BD Fix/Perm Solution Kit (BD Biosciences) and were analyzed using a FACSCalibur and FlowJo software (Tree Star Inc.).

\section{Statistical tests}

Standard error mean (SEM) were calculated for \% survival and \% IFN $\gamma$ production and are included in the Supporting Information Table 1. Correlation values were established by calculating Spearman rank-order correlation coefficient $\left(\mathrm{r}_{\mathrm{s}}\right)$ using VassarStats website (http://faculty.vassar.edu/lowry/VassarStats.html).

\section{Supplementary Material}

Refer to Web version on PubMed Central for supplementary material.

\section{Acknowledgments}

We would like to thank Josie Babin, Kevin Du Clos, Matthew Maybeno, Lori, Giancola, Jean Glenn and Carla Oseroff for technical support. AS was supported by NIH contract number HHSN266200400024C, MC by NIH grant AI67341. This is Kirin Pharma USA publication number 1042.

\section{Abbreviations}

$\begin{array}{ll}\text { ICCS } & \text { intracellular cytokine staining } \\ \text { VACV } & \text { vaccinia virus } \\ \text { WR } & \text { Western reserve } \\ \mathbf{r}_{\mathbf{s}} & \text { Spearman rank-order coefficient }\end{array}$

\section{References}

1. Xu R, Johnson AJ, Liggitt D, Bevan MJ. Cellular and humoral immunity against vaccinia virus infection of mice. J Immunol. 2004; 172:6265-6271. [PubMed: 15128815]

2. Fang M, Sigal LJ. Antibodies and CD8+ T cells are complementary and essential for natural resistance to a highly lethal cytopathic virus. J Immunol. 2005; 175:6829-6836. [PubMed: 16272340] 
3. Belyakov IM, Earl P, Dzutsev A, Kuznetsov VA, Lemon M, Wyatt LS, Snyder JT, Ahlers JD, Franchini G, Moss B, Berzofsky JA. Shared modes of protection against poxvirus infection by attenuated and conventional smallpox vaccine viruses. Proc Natl Acad Sci U S A. 2003; 100:94589463. [PubMed: 12869693]

4. Karupiah G, Buller RM, Van Rooijen N, Duarte CJ, Chen J. Different roles for CD4+ and CD8+ T. lymphocytes and macrophage subsets in the control of a generalized virus infection. J Virol. 1996; 70:8301-8309. [PubMed: 8970949]

5. Drexler I, Staib C, Kastenmuller W, Stevanovic S, Schmidt B, Lemonnier FA, Rammensee HG, Busch DH, Bernhard H, Erfle V, Sutter G. Identification of vaccinia virus epitope-specific HLAA*0201-restricted T cells and comparative analysis of smallpox vaccines. Proc Natl Acad Sci U S A. 2003; 100:217-222. [PubMed: 12518065]

6. Snyder JT, Belyakov IM, Dzutsev A, Lemonnier F, Berzofsky JA. Protection against lethal vaccinia virus challenge in HLA-A2 transgenic mice by immunization with a single CD8+ T-cell peptide epitope of vaccinia and variola viruses. J Virol. 2004; 78:7052-7060. [PubMed: 15194781]

7. Tscharke DC, Karupiah G, Zhou J, Palmore T, Irvine KR, Haeryfar SM, Williams S, Sidney J, Sette A, Bennink JR, Yewdell JW. Identification of poxvirus CD8+ T cell determinants to enable rational design and characterization of smallpox vaccines. J Exp Med. 2005; 201:95-104. [PubMed: 15623576]

8. Yewdell JW, Bennink JR. Immunodominance in major histocompatibility complex class I-restricted T lymphocyte responses. Annu Rev Immunol. 1999; 17:51-88. [PubMed: 10358753]

9. Moutaftsi M, Peters B, Pasquetto V, Tscharke DC, Sidney J, Bui HH, Grey H, Sette A. A consensus epitope prediction approach identifies the breadth of murine $\mathrm{T}(\mathrm{CD} 8+)$-cell responses to vaccinia virus. Nat Biotechnol. 2006; 24:817-819. [PubMed: 16767078]

10. Oseroff C, Kos F, Bui HH, Peters B, Pasquetto V, Glenn J, Palmore T, Sidney J, Tscharke DC, Bennink JR, Southwood S, Grey HM, Yewdell JW, Sette A. HLA class I-restricted responses to vaccinia recognize a broad array of proteins mainly involved in virulence and viral gene regulation. Proc Natl Acad Sci U S A. 2005; 102:13980-13985. [PubMed: 16172378]

11. Pasquetto V, Bui HH, Giannino R, Banh C, Mirza F, Sidney J, Oseroff C, Tscharke DC, Irvine K, Bennink JR, Peters B, Southwood S, Cerundolo V, Grey H, Yewdell JW, Sette A. HLA-A*0201, HLA-A*1101, and HLA-B*0702 transgenic mice recognize numerous poxvirus determinants from a wide variety of viral gene products. J Immunol. 2005; 175:5504-5515. [PubMed: 16210659]

12. Bronte V, Carroll MW, Goletz TJ, Wang M, Overwijk WW, Marincola F, Rosenberg SA, Moss B, Restifo NP. Antigen expression by dendritic cells correlates with the therapeutic effectiveness of a model recombinant poxvirus tumor vaccine. Proc Natl Acad Sci U S A. 1997; 94:3183-3188. [PubMed: 9096367]

13. Chahroudi A, Chavan R, Kozyr N, Waller EK, Silvestri G, Feinberg MB. Vaccinia virus tropism for primary hematolymphoid cells is determined by restricted expression of a unique virus receptor. J Virol. 2005; 79:10397-10407. [PubMed: 16051832]

14. Liu L, Xu Z, Fuhlbrigge RC, Pena-Cruz V, Lieberman J, Kupper TS. Vaccinia virus induces strong immunoregulatory cytokine production in healthy human epidermal keratinocytes: a novel strategy for immune evasion. J Virol. 2005; 79:7363-7370. [PubMed: 15919891]

15. Norbury CC, Malide D, Gibbs JS, Bennink JR, Yewdell JW. Visualizing priming of virus-specific CD8+ T cells by infected dendritic cells in vivo. Nat Immunol. 2002; 3:265-271. [PubMed: $11828323]$

16. Drillien R, Spehner D, Bohbot A, Hanau D. Vaccinia virus-related events and phenotypic changes after infection of dendritic cells derived from human monocytes. Virology. 2000; 268:471-481. [PubMed: 10704355]

17. Engelmayer J, Larsson M, Subklewe M, Chahroudi A, Cox WI, Steinman RM, Bhardwaj N. Vaccinia virus inhibits the maturation of human dendritic cells: a novel mechanism of immune evasion. J Immunol. 1999; 163:6762-6768. [PubMed: 10586075]

18. Jenne L, Hauser C, Arrighi JF, Saurat JH, Hugin AW. Poxvirus as a vector to transduce human dendritic cells for immunotherapy: abortive infection but reduced APC function. Gene Ther. 2000; 7:1575-1583. [PubMed: 11021596] 
19. Crowe SR, Miller SC, Woodland DL. Identification of protective and non-protective T cell epitopes in influenza. Vaccine. 2006; 24:452-456. [PubMed: 16140438]

20. Crowe SR, Turner SJ, Miller SC, Roberts AD, Rappolo RA, Doherty PC, Ely KH, Woodland DL. Differential antigen presentation regulates the changing patterns of CD8+ T cell immunodominance in primary and secondary influenza virus infections. J Exp Med. 2003; 198:399-410. [PubMed: 12885871]

21. Botten J, Whitton JL, Barrowman P, Sidney J, Whitmire JK, Alexander J, Ting JP, Bui HH, Sette A, Buchmeier MJ. HLA-A2-restricted protection against lethal lymphocytic choriomeningitis. J Virol. 2007; 81:2307-2317. [PubMed: 17166907]

22. Assarsson E, Greenbaum JA, Sundstrom M, Schaffer L, Hammond JA, Pasquetto V, Oseroff C, Hendrickson RC, Lefkowitz EJ, Tscharke DC, Sidney J, Grey HM, Head SR, Peters B, Sette A. Kinetic analysis of a complete poxvirus transcriptome reveals an immediate-early class of genes. Proc Natl Acad Sci U S A. 2008; 105:2140-2145. [PubMed: 18245380]

23. Cochran MA, Puckett C, Moss B. In vitro mutagenesis of the promoter region for a vaccinia virus gene: evidence for tandem early and late regulatory signals. J Virol. 1985; 54:30-37. [PubMed: 3973982]

24. Kastenmuller W, Gasteiger G, Gronau JH, Baier R, Ljapoci R, Busch DH, Drexler I. Crosscompetition of CD8+ T cells shapes the immunodominance hierarchy during boost vaccination. J Exp Med. 2007; 204:2187-2198. [PubMed: 17709425]

25. Ohno S, Moriya O, Yoshimoto T, Hayashi H, Akatsuka T, Matsui M. Immunogenic variation between multiple HLA-A*0201-restricted, Hepatitis C Virus-derived epitopes for cytotoxic T lymphocytes. Viral Immunol. 2006; 19:458-467. [PubMed: 16987064] 

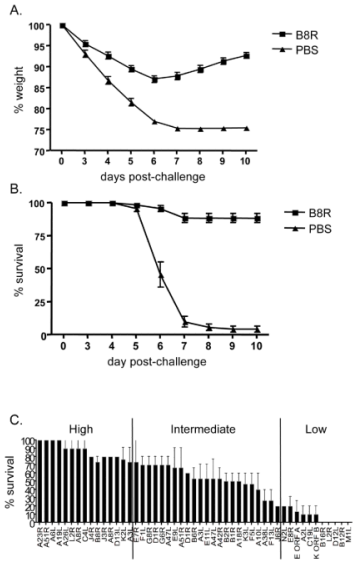

Figure 1. Wide variation of protection efficacy induced by individual epitopes

Peptide-immunized mice (see the Materials and methods) were challenged i.n. with a lethal dose of VACV. Body weight was calculated as percentage of the mean weight for each group on the day of challenge. Survival and weight loss were used as parameters of disease course and protection efficacy was measured as percent survival and based on weight loss. PBS-immunized mice were used as controls in each experiment. The average of 14 independent experiments each with 5 mice/group are represented as (A) \% weight and (B) \% survival for peptide (B8R $20-27$, squares) and control (PBS, triangles). The significance of percent survival data was assessed as follows: Out of 75 control mice (PBS-immunized) a total of $5(=6.67 \%)$ survived 10 days after challenge. Observing a survival of $25 \%$ or higher in a group of 10 peptide-immunized mice has a chance probability of $\mathrm{p}=0.0249$ using the binomial distribution. For groups of 15 mice, observing a survival of $25 \%$ or higher corresponds to $\mathrm{p}=0.0149$, which is also below the customary cutoff of $5 \%$. Therefore $25 \%$ survival was used as the minimal threshold for significant protection. (C) All 49 epitopes were tested in 2-3 experiments each with 5 mice/group. SEM values are shown for \% survival. 


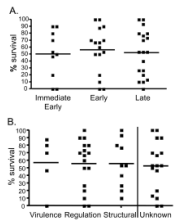

Figure 2. Neither expression kinetics nor functional category of viral protein correlate with protection efficacy

Protection efficacy (based on \% survival data obtained from weight loss following lethal i.n. challenge with VACV of peptide-immunized mice, described in detail in Figure legend 1 and Material and methods) of each of the 49 epitopes was correlated with the appropriate viral protein-containing epitopes each categorized according to their (A) expression kinetics (divided into immediate-early, early and late gene expression profiles $[22,23])$ or (B) functional category. Correlation values were established by calculating Spearman rank-order correlation coefficient $\left(\mathrm{r}_{\mathrm{s}}\right)$. No significant correlation was observed between protection efficacy and antigen expression kinetics or function. 


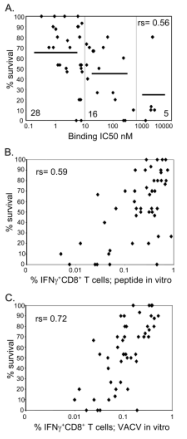

Figure 3. Factors contributing to prediction of protection efficacy

(A) Binding affinity based on IC50 values (described in Material and methods and [9]) were correlated with protection efficacy (based on \% survival data obtained from weight loss following lethal i.n. challenge with VACV of peptide-immunized mice, described in detail in Figure legend 1 and Material and methods). Splenocytes from peptide-immunized mice were stimulated with (B) peptide-pulsed or (C) VACV-infected APC (DC2.4, MOI 10, described in Material and methods) in vitro and tested for IFN- $\gamma$ production by ICCS assays. Background levels in ICCS assays were established from samples pulsed with DMSO and subtracted from the experimental values. Sample values greater than background were considered positive. Between 2-4 independent experiments were performed testing a total of 4-11 mice/epitope and mean values were correlated with \% survival. Correlation values were established by calculating Spearman rank-order correlation coefficient $\left(\mathrm{r}_{\mathrm{s}}\right)$. Significant correlation was observed between $\%$ survival and MHC binding affinity of the peptides (A) as well as IFN- $\gamma$ induction following peptide stimulation (B). Most significant correlation was observed between $\%$ survival and IFN- $\gamma$ induction following stimulation with VACVinfected APC (C). 